\title{
The Current State Analysis and Countermeasure on the Upland crops Production in Ningbo, Yinzhou District
}

\author{
Xiaoting Tan ${ }^{1, a}$ and Wanzhen Huang ${ }^{1, b}$ \\ 1Shenyang Agricultural University, Shenyang 210000, China \\ atanxtsyau@163.com, b625114502@qq.com
}

Keywords: Yinzhou district; Upland crops production; Agricultural policy

\begin{abstract}
Upland crop is one of the important components in the grain production in Ningbo, Yinzhou District. However, with the gradual upgrading of agricultural industrial structure, regulating of agricultural policy guidance and improving of agricultural production technologies, the production of upland crops faces many difficulties, such as technical backwardness, low concern, low yield and poor economic benefits for a long time. In order to conquer these issues and increase the profits of upland crops production, this paper analyzed the existed problems by various methods including investigation and visit, data analysis and policy interpretation, etc. This paper puts forwards policy recommendations on increasing the degree of attention on upland crops production, enhancing scientific supports, achieving large-scale production and establishing demonstration bases, etc.
\end{abstract}

\section{Introduction}

Upland crops is also called coarse cereals, which includes all kinds of grain crops such as wheat, barley, maize, sweet potatoes, potatoes, soybeans, broad beans, peas, miscellaneous beans, sorghum, buck wheats and other grains except rice. In general, upland crops has plenty advantages such as widely adaptability to a wide range, high efficiency in land-use, numerous alternative varieties as well. Therefore, it has good prospects of planting. According to Plans on Planting Structure Adjustment in Zhejiang Province (2016-2020), the government appealed that people should insist the principle of developing the suitable cropping patterns to local conditions meanwhile giving priority to rice planting. It also says people need to enrich the assortments of upland crops, optimize the regional distribution of upland crops, and promote the industrial development of upland crops.

Under such circumstance, this paper summarized the issues on upland crops planting by investigating in Ningbo, Yinzhou District and rea-ding relevant historical data, several policy measures are provided for increasing economic efficiency on upland crops in Yinzhou District.

\section{The Present of Upland Crops Production in Yinzhou District}

Yinzhou District is located in the south of the Yangtze River Delta where belongs to moderate subtropical monsoon climate. There are a variety of agricultural environments. The southeastern region and the Western region are hills and mountains, the soils in western appear as yellow soil. It is suitable to plant upland crops such as wheat, barley, maize, sweet potatoes, potatoes, soybeans, etc. Therefore, upland crop is an important part of grain production in Yinzhou district. The sown area of upland crops was more than $10 \%$ of the total sown area for a long time. A great variety of upland crops are planted in Yinzhou District such as wheat, barley, maize, sweet potatoes, potatoes, soybeans, miscellaneous beans sorghum and so on.

Changes in sown area of upland crops in Yinzhou District. The total sown area of upland crops shows that the tendency of it is to increase at first and then drop. The area planted upland crops reached 3.2 ten thousand mu in 1949, since then the area shows a slow upward tendency, till 1980 s the peak value of upland crops sown area appeared as 21.77 ten thousand mu. From that time, 
the area decreased year by year. In 1991,the sown area dropped to 3.24 ten thousand mu, until the $21 \mathrm{~s}$ the sown areas of upland crops increased to about 5 ten thousand mu-7 ten thousand mu, the upland crops area was 7.2 ten thousand mu in 2016. The fundamental causes of the changes in sown area of upland crops are as followed first is to fit in the adjustment of agricultural structure, secondly, the income of peasants who plant rice is higher than the peasants who plant upland crops so that the expansion of rice planting area and the decrease of others planting area. The sown area of some varieties of farm products even sharply reduced due to production structure changes.

Take wheat and barley as an example, in the1980s under the circumstances that the strong policy of the government drove, the sown area of planting upland crops reach the peak value. Since then the sown area declines linearly because of the second agricultural structure adjustment. The sown area of barley in 1981 and 1995 are 1.735 ten thousand mu and 0.24 ten thousand mu, the sown area of wheat are 3.14 ten thousand mu and 0.01 ten thousand mu,in 2005, the sown area of wheat is just 0.003 ten thousand mu.

Table 1 The sown area of major upland crops in Ningbo City, Yinzhou District

Unit: ten thousand $\mathrm{Mu}$

\begin{tabular}{cccccc}
\hline & Barley & Wheat & Maize & Broad beans & Sweet potatoes \\
\hline 1981 & 17.35 & 3.14 & 0.09 & 0.36 & 0.83 \\
1991 & 2.69 & 0.01 & $/$ & 0.22 & 0.32 \\
1995 & 0.24 & 0.01 & 0.1 & 0.53 & 0.48 \\
2005 & 0.01 & 0.003 & 0.48 & 1.05 & 0.93 \\
2014 & 0.2 & 2.44 & 1.18 & 0.9 & 0.9 \\
2016 & 0.24 & 2.63 & 1.05 & 1.49 & 0.70 \\
\hline
\end{tabular}

Since 2007, government in Ningbo Province has provided aid to farmers who plant upland crops by agricultural subsidy policies. That is making an allowance of 20 yuan per mu for the farmers who plant upland crops more than $20 \mathrm{mu}$ or plant thorough mechanization-produced upland crops or accept the whole process unified service provided by social service organization. This policy arouse peasants' enthusiasm for planting wheat and barley, production of wheat increased to 2.44 ten thousand $\mathrm{mu}$ in 2014.Due to the subsidy policies of barley, the sown area also increased from 0.01 ten thousand mu to 0.2 ten thousand mu.

In 2016, the government in Ningbo Province strengthened the financial support for upland crops cultivation. Firstly, they increased policy subsidy for upland crops cultivation insurance, extended the coverage of policy subsidy for upland crops cultivation insurance, meanwhile hiked up the price of compensation for natural disaster, the price of compensation of wheat was increased to 500 yuan per mu. Secondly, the government integrated previous financial support policies for wheat and barley to subsidize more than 100 yuan per $\mathrm{Mu}$ for large-scale upland crops owners whose management area is more than $50 \mathrm{mu}$ (including $50 \mathrm{mu}$ ) and the sown area of grain is more than 50 mu per year. As a result, the sown areas of wheat and barley were being further extended. The area of barley was 0.24 ten thousand mu and the area of wheat was 2.63 ten thousand mu.

Change of upland crops yield in Yinzhou District. Similar to the sown area of upland crops production, total upland crops yield also underwent the process of increasing at the first and then dropping in the past 60 years. During the initial period of China, the yield of upland crops was 0.2 ten thousand mu, it increased to 4.4 ten thousand mu until 1981.After that, with the decrease of sown area, total yield of upland crops also declined, which reached its lowest value 0.52 million tons in 1991.And then went through a period of low yield of upland crops production, the total yield of upland crops was about 1milion tons. In 2003 it was only about 0.94 million tons. Later, with the preferential policies to upland crops, the yield rose slightly, it basically kept stable at around 
2 million tons for the past five years.

Compared with fluctuating of total yield, the average yield of upland crops showed the tendency on increasing. It increased by $318 \%$ in 2013 compared with it in 1949.However,the average yield of upland crops in Yinzhou District remained at low levels. In 2016,the average yield of upland crops was $330 \mathrm{~kg} / \mathrm{mu}$, it was far below the average yield of rice. And it marked a sharp contrast with the fact, which high yield cultivation of rice in Yinzhou District broke through national record. We take wheat as an example, in 2015 which is the good harvest year, the average yield was $335 \mathrm{~kg} / \mathrm{mu}$, it was just at low level of the national average value. In other years without the agricultural disaster situation, the average yield is only hovering at around 300 kilograms.

Changes of agriculture policies in Yinzhou District. The pattern of grain production in Yinzhou District is regarding rice cultivation as the dominant position and upland crops cultivation as the subsidiary. In the 1980s, upland crops cultivation had been emphasized by Yinzhou District government. However, with the gradual settlement of the problem of food and clothing for the poor in rural, there were no corresponding policies for upland crops, such as there was neither direct subsidy policies and seed subsidies for upland crops, nor agricultural insurance for upland crops varieties.

However, with the growth in the living standards and consumer's multiple needs, the status of upland crops cultivation has been greatly elevated. General office of the people's government of Zhejiang Province has made a document named Opinions on accelerating development of upland crops cultivation. The Opinions suggests that the government should focus on developing upland crops cultivation on uplands which includes winter fallow fields, low hilly woodlands, garden plots and mountainous, etc. They aim to expand the sown area of upland crops more than $1 \mathrm{million} \mathrm{mu}$ on the basis of the sown area in 2013. And aim to increase output more than 0.3 million tons per year and increase the average yield of upland crops more than $10 \%$.

Yinzhou District agricultural department fully implement the suggestions of The Opinion, they subsidized the large-scale farm where planted wheat and barley, carried out activities of high yield and high efficiency demonstration base for upland crops, gave subsidies to the demonstration base which identified by agricultural sector. Meanwhile, they required various towns (streets) vigorously to promote the use of new species, new technologies, new machines and tools on this account.

\section{Existing Problems in Upland Crops in Yinzhou District}

Less attention and less relevant supportive policies on upland crops. Although the government is promoting the development of upland crops cultivation, the attentions and related supportive policies are still insufficient. The enthusiasm of farmers to plant upland crops has been low because in the past long period of time, upland crops have not enjoyed the direct subsidy policies and seed subsidy policies like rice.

Comparing with other districts and counties, there is no specific documents in Yinzhou District agricultural department to guide peasants to develop upland crops. Peasants don't have an adequate under-standing of upland crops cultivation and development. They plant upland crops scattered because they regard upland crops as a sideline of rice. The agricultural scientific research and agricultural technology extension team also give the first place to rice cultivation, they lack of special agricultural technology personnel to engage in research and promotion of upland crops technology. Besides, the cultivation techniques of upland crops with high yield and high efficiency are few. Such conditions affected the development of upland crops production seriously.

Extensive cultivation techniques and backward varieties of upland crops. In Yinzhou District, grain-production households widely use extensive management of the upland crops. In the 134 households which the author randomly interviewed who planted upland crops ,most of them planted upland crops after planted rice or vegetables. There were few large-scale upland crops production households among the 134 samples. Besides, the age of the farmers who planted upland crops were generally old, the proportion of famers over 35 years old was $83.2 \%$. They generally had low level of education, $62.5 \%$ of them were under junior high school educated degree. They seldom took the initiative activities to adopt advanced cultivation techniques or find good varieties of 
upland crops. So that planting level and technology content of upland crops was extremely low.

Besides, there is a serious shortage of upland-crops-technicians in agro-tech departments of Yinzhou District. At present, there are 26 agricultural technology extension workers but none of them are full-time responsible for upland crops production, 2 of them take part-time responsibility. Almost all of them are rice cultivation technicians. The upland crops sown area in 2016 is about 7 ten thousand $\mathrm{mu}$, the proportion of technical personnel and planting area is 1:3.7 mu. It is even more difficult to find part-time staffs in the township agro-tech departments. So it is difficult to carry out the training and guiding of the cultivation of upland crops. In addition to staffing, policy oriented also affect the upland crops production. Many advanced techniques and excellent varieties of upland crops can not be promoted and demonstrated systematically, and the technical guidance of upland crops production is basically in the blank or semi blank state in some areas.

Meanwhile, during the processing on upland crops production, most of the farmers use traditional varieties or use the seed reserved by themselves. It is found in investigation, except soybean, corn, wheat and potatoes, many of the upland crops in Yinzhou District have no scientific and technological department or individuals engaged in selecting the good varieties. The result is that varieties do not change for decades and lead to many problems such as serious varietal hybridization, low yield and low quality. Even if several varieties have been approved, they are also affected by the inertia thinking of "rice is important than upland crops", so that the extension strength is weak and the sown area of such varieties is small.

High labor intensity and low efficiency. The dry lands in Yinzhou District are scattered distributed. Besides, there are many problems which are embodied in the outdated infrastructure, poor soil fertility, difficulty to popularize agricultural machinery, low degree of agricultural mechanization, etc. Above all, it is not capable of machinery cultivation and mechanical transportation for upland crops production in Yinzhou District. Planting and harvest of upland crops basically completed by hand that is time-consuming and high labor intensity, it also lead to high cost. Even though the wheat which sown area is generally 2 ten thousand mu, the mechanization level is also low. The sown pattern's is by drilling. And most of the peasants have not participated in the specialized and uniform pest specialized unified prevent service, only when wheat is mature, they hire machineries to harvest.

Due to the problems above, planting benefits of upland crops in Yinzhou District is low meanwhile farmers' willingness and enthusiasm of growing upland crops is very weak. Let's take wheat as an example, in 2013 a large-scale upland crops production households planted $150 \mathrm{mu}$ of wheat in Yinzhou District Hengjie Town, they got a subsidy of 60 yuan/mu by cooperated with the municipal agro-tech departments on science and technology project and got a subsidy for seed of 15-20 yuan/mu by the district department. The yield of wheat was about $300 \mathrm{~kg} / \mathrm{mu}$, and the purchase price was 1.5-2 yuan $/ \mathrm{kg}$. Except the rent charge of the field, it just kept balance between the income and the expenditure, it was hard to make a profit. So the situation of the large-scale upland crops production households was just like this, the difficulty of small-scale to make the economic benefits is imaginable.

\section{Policy Suggestions on Developing Upland Crops Production in Yinzhou District}

To strength conduct propaganda and pay more attention on upland crops production. There is a great variety of upland crops. And it has the features of low demand of soil, irrigation and other conditions. It also has the characteristics of wide adaptability and low management cost. It can effectively reduce the occurrence of farmland diseases and insect pests through the rice field-upland field rotation. Developing upland crops production is beneficial to achieve the goal of grain production, to optimize the planting structure of upland crops, to improve the agricultural comprehensive production capacity and to reduce seasonal land abandoned. It is also beneficial to increase farmers' income and improve agricultural efficiency. The agricultural department should raise the emphasis on the upland crops production, they should give financial subsidies including superior seed varieties subsidy, mechanization of agriculture operations subsidy, pesticide subsidy, agricultural film subsidy, fertilizer subsidy and so on to upland crops by season and area. They 
should add fresh upland crops and upland crop sin vegetables into the vegetable category. According to the requirements of upgrades rice and vegetable industry project in Zhejiang province, they should carry out the industry promotion project to conditional characteristic upland crops varieties. Through the implementation of the project, they should accelerate technological innovation and promote advanced technologies at the same time build and perfect the infrastructures of upland crops production.

As for upland crops production demonstration, they can also imitate the rice production to develop high yield activities of upland crops. In the last few years, agricultural department in Yinzhou District has been trying to set up the activities of the ten thousand mu area of high-yield rice, it has made remarkable achievements in increasing the yield of per unit area and total rice production. Upland crops production can also follow this model of rice production, declare the activities of the thousand mu area of high-yield upland crops actively and carry out activities of upland crops high yield competition in an all-round way and create a good atmosphere of setting up high yield of upland crops.

To strength scientific and technological support on upland crops and increase efforts to promote superior seed upland crops varieties and planting methods. The department of agriculture in Yinzhou District should vigorously implement the strategy of "increasing grain production through science and technology". They should strengthen the combination of agriculture, science and education, strengthen the cooperation of scientific and technology on upland crops production, strength key technology research of upland crops cultivation, accelerate the integration and innovation of high yield and quality varieties green standardization production of upland crops. They should make the positive use of industrial technology team and strengthen the construction of agricultural science and technology talents at grass-roots unit. They should intensify the cultivating of the updating the agricultural technicians' knowledge and enhancing their professional quality and the ability to serve the upland crops production households. They should carry out agricultural vocational education and skill training widely to enhance farmers' ability to accept agricultural technology of upland crops. They should regard breeding and selection of improved varieties and integration of cultivation techniques as the driving force of upland crops production.

Promoting the integration of industrial chain and developing scale production. They need to guide the farmers to willingly carry out the exchange of land, farmland, wasteland and guide them to paid subcontract so that make the almost contiguous upland concentrated on the land expert in order to develop large-scale production. Priority which include technical support, fund support or appropriate incentives should be given to large-scale grain-production households, specialized farmers cooperatives and agricultural technology departments who develop upland crops production actively. They should strength infrastructure constructions including land management, water conservancy facilities, tractor-ploughing roads, etc. They should promote production capacity of upland crops, strive to achieve mechanization production, scale production and industrialization production. And promote upland crops production to form a virtuous circle of "multi input, high output, high benefit, increase investment and expand reproduction".

\section{Acknowledgements}

Supported by the Foundation of Liaoning Province Philosophy and Social Science Planning (L17CJY008), and Science Foundation of Ministry of Education of China (13YJC790129).

\section{References}

[1] R.X. Cai, Y.J.Wang and Z G Wu: Present situation and Development Countermeasures of dry grain production in Zhejiang Province. Journal of Zhejiang agricultural sciences, (2012) No.12, p.1607-1610.

[2] AP Barkley. Wheat price policy in Pakistan: A welfare economics approach. The Pakistan Development Review, Vol. 31 (1992) No.4, p.1145-1156. 
[3] T S Jayne, R J Myers and J Nyoro: The effects of NCPB marketing policies on maize market prices in Kenya. Agricultural Economics, Vol. 38 (2008) No.3, p.313-325.

[4] S Z Ali, R S Sidhu and K Vatta: Effectiveness of minimum support price policy for paddy in India with a case study of Punjab. Agricultural Economics Research Review, Vol. 25 (2012) No.2, p.231-242.

[5] P.Sckokai and J.Anton: The degree of decoupling of area payments for arable crops in the European Union. American Journal of Agricultural Economics, Vol.87(2005)No.5,p.1220-1228. 